\title{
What Causes Some Patients with Drug-Induced QT Interval Prolongation to Develop Torsades de Pointes but Not Others? The Elusive Missing Link
}

\author{
James E. Tisdale
}

Published online: 15 July 2014

(C) Springer International Publishing Switzerland 2014

Cardiac arrest due to torsades de pointes (TdP) is an uncommon but potentially catastrophic event associated with QT interval-prolonging drugs [1]. Numerous medications that may cause TdP are available for use in clinical practice, and include drugs for management of cardiovascular diseases, primarily arrhythmias, but also noncardiovascular agents from multiple classes, including antiinfectives, antipsychotics, antidepressants, methadone, and many more [2]. The risk of TdP increases as the heart ratecorrected QT $\left(\mathrm{QT}_{\mathrm{c}}\right)$ interval increases [3-6], particularly when it exceeds $500 \mathrm{~ms}[5,6]$. Numerous independent risk factors for $\mathrm{QT}_{\mathrm{c}}$ interval prolongation and $\mathrm{TdP}$ have been identified, and include female sex, hypokalemia, hypomagnesemia, acute myocardial infarction, sepsis, supratherapeutic concentrations of $\mathrm{QT}_{\mathrm{c}}$ interval-prolonging drugs, rapid intravenous infusion of $\mathrm{QT}_{\mathrm{c}}$ interval-prolonging drugs, concomitant administration of two or more $\mathrm{QT}_{\mathrm{c}}$ interval-prolonging drugs, concomitant administration of a loop diuretic, bradycardia, heart failure with reduced ejection fraction $(\mathrm{HFrEF})$, pretreatment $\mathrm{QT}_{\mathrm{c}}$ interval prolongation, and ion channel polymorphisms [7,8].

Some evidence indicates that older age is also a risk factor for prolonged $\mathrm{QT}_{\mathrm{c}}$ interval [8-10] and $\mathrm{TdP}$ [11]. In

This comment refers to the article available at doi:10.1007/s40266-014-0188-y.

\section{J. E. Tisdale ( $($ )}

The Department of Pharmacy Practice, College of Pharmacy, Purdue University, 640 Eskenazi Avenue,

Indianapolis, IN 46202, USA

e-mail: jtisdale@purdue.edu

\section{J. E. Tisdale}

Division of Clinical Pharmacology, Department of Medicine,

School of Medicine, Indiana University, Indianapolis, IN, USA the Third National Health and Nutrition Examination Survey (NHANES III), age was associated with prolonged $\mathrm{QT}_{\mathrm{c}}$ interval in men [8]. In a study of hospitalized patients, age $>60$ years was reported to be a risk factor for druginduced QT interval prolongation [9]. In another study of hospitalized patients, age $\geq 68$ years was shown to be an independent risk factor for $\mathrm{QT}_{\mathrm{c}}$ interval prolongation in patients in cardiac care units [10]. Age $\geq 65$ years is an independent risk factor for TdP associated with azimilide [11]. Mechanisms underlying an increased risk of druginduced $\mathrm{QT}_{\mathrm{c}}$ interval prolongation and $\mathrm{TdP}$ in older patients are unclear, but could include declining serum testosterone concentrations in older men $[12,13]$ and reduced serum progesterone concentrations in postmenopausal women [14]. $\mathrm{QT}_{\mathrm{c}}$ interval-prolonging medications are prescribed commonly to older patients [15]; therefore, awareness of the degree of risk and strategies for mitigating the risk of $\mathrm{QT}_{\mathrm{c}}$ interval prolongation and $\mathrm{TdP}$ in this population are desirable. Although it is known that the risk of $\mathrm{TdP}$ increases as the $\mathrm{QT}_{\mathrm{c}}$ interval increases, there is a missing link; only a small portion of patients that develop drug-induced $\mathrm{QT}_{\mathrm{c}}$ interval prolongation experience TdP. It is unknown why some patients with drug-induced $\mathrm{QT}_{\mathrm{c}}$ interval prolongation experience TdP and some do not, and whether there are risk factors that predispose patients with drug-induced QT interval prolongation to develop TdP. Information that could shed light on this mystery would advance the field and contribute important knowledge regarding mitigation of TdP risk.

In this issue of Drugs and Aging [16], Goutelle and colleagues attempt to identify factors that predispose elderly patients with drug-associated long $\mathrm{QT}_{\mathrm{c}}$ interval to development of TdP. In this retrospective, case-control study, the investigators queried the national French pharmacovigilance database for cases of long $\mathrm{QT}_{\mathrm{c}}$ interval and 
TdP occurring in patients $\geq 65$ years of age during the years 2000-2009. The cases were divided into two groups: (1) patients who developed drug-induced long $\mathrm{QT}_{\mathrm{c}}$ interval (defined as QT or $\mathrm{QT}_{\mathrm{c}}$ interval $>450 \mathrm{~ms}$ ) and also experienced $\operatorname{TdP}(n=125)$, and (2) patients who developed drug-induced long $\mathrm{QT}_{\mathrm{c}}$ interval but did not develop TdP ( $n=81)$. Drugs that were most commonly associated with $\mathrm{QT}_{\mathrm{c}}$ interval prolongation and/or TdP included amiodarone, furosemide, digitalis drugs, and sotalol, among others. Univariate comparison of the two groups demonstrated significantly higher odds ratios for TdP associated with uncorrected (but not corrected) QT interval, digitalis drugs, and a mixed group of other potential drug culprits. However, multivariate regression analysis revealed only one independent risk factor for TdP, which was uncorrected QT interval (odds ratio 1.013, $95 \%$ confidence interval 1.004-1.022, $p=0.0014)$.

Limitations of this study acknowledged by the investigators include its retrospective case-control design, although in fairness, a prospective, randomized, controlled study to determine risk factors that predispose patients to TdP would not be feasible. Nonetheless, the study design is subject to the biases inherent in retrospective studies of spontaneous reporting databases, including potential underreporting of events, notoriety bias, and variable data quality and integrity. Other limitations include the fact that the investigators relied upon QT interval measurements reported in the database, and there was not an opportunity to verify the accuracy of QT interval measurements using a consistent method of assessment. Because of the nature of the data, patients with QRS duration $>120 \mathrm{~ms}$, including those with left bundle branch blocks and functioning ventricular pacemakers, were not excluded; this can affect the accuracy of the QT interval measurements, and it is unknown whether the distribution of such patients varied between the two study groups. The method for the heart rate correction of the QT intervals was not available in the majority of the reports. The definition of drug-induced long QT interval syndrome used in the study was $\mathrm{QT}_{\mathrm{c}}>450 \mathrm{~ms}$. However, the upper limits of normal for $\mathrm{QT}_{\mathrm{c}}$ interval in men and women are 470 and $480 \mathrm{~ms}$, respectively [1]. In addition, the majority of data have identified a $\mathrm{QT}_{\mathrm{c}}$ interval $>500 \mathrm{~ms}$ as the point at which the risk of TdP increases markedly [5-7]; this may be a more appropriate definition of drug-induced long QT interval syndrome.

Despite these limitations, there is merit in the analysis of Goutelle and colleagues [16], as it remains unknown whether there are specific factors that predispose patient with prolonged $\mathrm{QT}_{\mathrm{c}}$ interval to develop $\mathrm{TdP}$, and whether there are identifiable differences between patients with prolonged $\mathrm{QT}_{\mathrm{c}}$ interval that develop TdP and those who do not. The results of their analysis are surprising, in that widely accepted risk factors for TdP including female sex, hypokalemia, and heart disease (including HFrEF) did not emerge as independent risk factors for TdP. This could be due to some or all of the aforementioned limitations of the study. Alternatively, it is possible that female sex, hypokalemia, heart disease and other risk factors contribute to lengthening of the $\mathrm{QT}_{\mathrm{c}}$ interval, but do not contribute additionally to the occurrence of TdP once the $\mathrm{QT}_{\mathrm{c}}$ interval is already prolonged. As this analysis was confined to patients $\geq 65$ years of age, it is also possible that the influence of some or all of these risk factors is lessened in older patients. These questions require further investigation.

Goutelle and colleagues [16] reported that uncorrected QT interval (but not the corrected QT interval) was the only independent predictor of TdP in this study. This could again be attributed to the aforementioned study limitations pertaining to QT interval measurements and/or correction, inclusion of patients with prolonged QRS duration, and/or definition of $\mathrm{QT}_{\mathrm{c}}$ interval prolongation. However, this finding is consistent with some previous data. In a study of critically ill patients who received intravenous haloperidol ( $n=46$ ) for delusional agitation, of whom $n=7$ developed TdP, uncorrected QT interval was a significantly better predictor of haloperidol-associated TdP than Bazett's or Fridericia-corrected QT interval [17]. Framingham-corrected QT interval offered no advantage over QT intervals not corrected for heart rate. Uncorrected QT interval measurements have been shown to be more reliable than Bazett's or Fridericia-corrected QT intervals [18]. In addition, heart rate correction of QT intervals is often performed inaccurately, even by physicians and cardiologists [19]. Use of uncorrected rather than heart rate-corrected QT intervals may offer advantages of simplicity and accuracy; further study is required to determine whether uncorrected QT interval can reliably replace heart ratecorrected QT interval for assessment of risk of TdP.

Goutelle and colleagues [16] attempted to identify factors that predispose elderly patients with drug-induced long QT interval syndrome to develop TdP. While their effort is important, the paucity of factors identified in their study leaves open questions that require further scientific inquiry, including the following: (1) Why do some patients with druginduced long QT interval develop TdP while others do not? (2) Are there as yet unidentified risk factors that predispose patients with drug-induced prolonged QT interval to develop TdP? (3) Does the influence of specific risk factors for TdP such as female sex, electrolyte abnormalities, heart disease, and others change or diminish with advancing age? As long as these and other important questions remain unanswered, the missing link remains elusive.

Acknowledgments Dr. Tisdale's work is supported by the American Heart Association Midwest Affiliate and the Strategic Research Initiative, Indiana Clinical Translational Sciences Institute. 


\section{References}

1. Drew BJ, Ackerman MJ, Funk M, Gibler WB, Kligfield P, Menon V, Philippides GJ, Roden DM, Zareba W, American Heart Association Acute Cardiac Care Committee of the Council on Clinical Cardiology, the Council on Cardiovascular Nursing, and the American College of Cardiology Foundation. Prevention of torsade de pointes in hospital settings: a scientific statement from the American Heart Association and the American College of Cardiology Foundation. Circulation. 2010;121:1047-60.

2. CredibleMeds ${ }^{\circledR}$. http://www.crediblemeds.org/everyone/compositelist-all-qtdrugs/. Accessed 24 June 2014.

3. Zareba W, Moss AJ, Schwartz PJ, Vincent GM, Robinson JL, Priori SG, Benhorin J, Locati EH, Towbin JA, Keating MT, Lehmann MH, Hall WJ. Influence of genotype on the clinical course of the long-QT syndrome. International Long-QT Syndrome Registry Research Group. N Engl J Med. 1998;339:960-5.

4. Sharma ND, Rosman HS, Padhi ID, Tisdale JE. Torsades de pointes associated with intravenous haloperidol in critically ill patients. Am J Cardiol. 1998;81:238-40.

5. Moss AJ, Schwartz PJ, Crampton RS, Tzivoni D, Locati EH, MacCluer J, Hall WJ, Weitkamp L. The long QT syndrome. Prospective longitudinal study of 328 families. Circulation. 1991;84:1136-44.

6. Woosley RL, Chen Y, Freiman JP, Gillis RA. Mechanism of the cardiotoxic actions of terfenadine. JAMA. 1993;269:1532-6.

7. Roden DM. Drug-induced prolongation of the QT interval. N Engl J Med. 2004;350:1013-22.

8. Benoit SR, Mendelsohn AB, Nourjah P, Staffa JA, Graham DJ. Risk factors for prolonged QTc among US adults: Third National Health and Nutrition Examination Survey. Eur J Cardiovasc Rehabil. 2005;12:363-8.

9. Letsas KP, Efremidis M, Kounas SP, Pappas LK, Gavrielatos G, Alexanian IP, Dimopoulos NP, Filippatos GS, Sideris A, Kardaras F. Clinical characteristics of patients with drug-induced QT interval prolongation and torsade de pointes: identification of risk factors. Clin Res Cardiol. 2009;98:208-12.

10. Tisdale JE, Jaynes HA, Kingery JR, Mourad NA, Trujillo TN, Overholser BR, Kovacs RJ. Development and validation of a risk score to predict QT interval prolongation in hospitalized patients. Circ Cardiovasc Qual Outcomes. 2013;6:479-87.

11. Pratt CM, Al-Khalid HR, Brum JM, Holroyde MJ, Scwartz PJ, Marcello SR, Borggrefe M, Dorian P, Camm AJ. Cumulative experience of azimilide-associated torsades de pointes ventricular tachycardia in the 19 clinical studies comprising the azimilide database. J Am Coll Cardiol. 2006;48:471-7.

12. Zhang Y, Ouyang P, Post WS, Dalal D, Vaidya D, Blasco-Colmenares E, Soliman EZ, Tomaselli GF, Guallar E. Sex-steroid hormones and electrocardiographic QT-interval duration: findings from the third National Health and Nutrition Examination Survey and the Multi-Ethnic Study of Atherosclerosis. Am J Epidemiol. 2011;174:403-11.

13. van Noord C, Dörr M, Sturkenboom MCJM, Straus SMJM, Reffelmann T, Felix SB, Hofman A, Kors JA, Haring R, de Jong FH, Nauck M, Uitterlinden AG, Wallaschofski H, Witteman JCM, Völzke H, Stricker BHCh. The association of serum testosterone levels and ventricular repolarization. Eur J Epidemiol. 2010;25:21-8.

14. Seth R, Moss AJ, McNitt S, Zareba W, Andrews ML, Oi M, Robinson JL, Goldenberg I, Ackerman MJ, Benhorin J, Kaufman ES, Locati EH, Napolitano C, Priori SG, Schwartz PJ, Towbin JA, Vincent GM, Zhang L. Long QT syndrome and pregnancy. J Am Coll Cardiol. 2007;49:1092-8.

15. Curtis LH, Ostbye T, Sendersky V, Hutchison S, Allen LaPointe NM, Al-Khalob SM, Usdin Yasuda S, Dans PE, Wright A, Califf RM, Woodley RL, Schulman KA. Prescription of QT-prolonging drugs in a cohort of about 5 million outpatients. Am J Med. 2003;114:135-41.

16. Goutelle S, Sidolle E, Ducher M, Caron J, Timour Q, Nony P, Gouraud A. Determinants of torsades de pointes in older patients with drug-associated long QT syndrome: a case-control study. Drugs Aging. 2014; doi:10.1007/s40266-014-0188-y.

17. Tisdale JE, Kovacs R, Mi D, McCabe GP, Cariera BL, Sharma N, Rosman H. Accuracy of uncorrected versus corrected QT interval for prediction of torsade de pointes associated with intravenous haloperidol. Pharmacotherapy. 2007;27:175-82.

18. Gow RM, Ewald B, Lai L, Gardin L, Lougheed J. The measurement of the QT and QTc on the neonatal and infant electrocardiogram: a comprehensive reliability assessment. Ann Noninvasive Electrocardiol. 2009;14:165-75.

19. Viskin S, Rosovski U, Sands AJ, Chen E, Kistler PM, Kalman JM, Chavez LR, Torres PI, Cruz FFES, Centurion OA, Fujiki A, Maury P, Chen X, Krahn AD, Roithinger F, Zhang L, Vincent GM, Zeltser D. Inaccurate electrocardiographic interpretation of long QT: the majority of physicians cannot recognize a long QT when they see one. Heart Rhythm. 2005;2:569-74. 